\title{
The Family's Experience of Sharing the Care of a Person with Dementia with the Services in Specialized Day-Care Units
}

\author{
Margrét Gústafsdóttir \\ Faculty of Nursing, University of Iceland, Reykjavík, Iceland
}

Key Words

Day care · Dementia · Caregiving · Family · Interpretive phenomenology · Longitudinal interviews

\section{Abstract}

Background: Services in specialized day-care units for individuals with dementia are set up to enable these persons to live in their own home. The purpose of this paper is to discern the experiences of families with these services while caring for a close relative with dementia. Method: Longitudinal interviews with 8 family members were conducted. In total, 25 interviews were carried out over a period of 5 years. Results: The experience of these families of looking after a close person with dementia appeared to be influenced by (a) the multifaceted meaning of ties, (b) the perception of purposeful relief of the day-care services and (c) the progress of the disease. Conclusion: All families found the services of specialized day-care units both useful and pleasant. This kind of resource was shown to make everyday life much more manageable for all persons involved, most importantly for the patient with dementia.

(C) 2014 S. Karger AG, Basel

\section{Introduction}

It is well known that 'population ageing, sometimes called demographic ageing, is now a worldwide phenomenon' [1, p. 36]. At the same time, age is considered the main risk factor leading to dementia [2]. According to Traynor et al., 'dementia is the most likely condition to 
be associated with profound or severe core activity limitations among older people' [2, $\mathrm{p}$. 1949]. Activity limitations among older individuals often lead to a call for help from a person close to the older person, such as a relative or a family member. Schumacher et al. [3] point out that a family member is often the primary provider of care, at least for the time when frailty threatens the independence in old age. These authors define family caregiving as 'care that is provided in response to illness or functional impairments that exceeds the "normal" care or help provided within families' [3, p. 4].

The caregiving experience of families in the scenario of dementia diseases has been widely researched with regard to the demands of the care as well as to possible ways to relieve some of them [4]. Schulz and Martire point out that, though caregiving tasks may be distributed among family members or friends, 'the more typical scenario is that most care is provided by one individual' [5, p. 242]. This single individual is likely to be a woman, namely the spouse, adult daughter or daughter-in-law [3].

$\mathrm{Ng}$ draws upon the Confucian ethic of familial relations in light of filial piety and maintains that research shows that 'filial obligations now mean first and foremost respect for and maintaining social contact with older family members' [6, p. 305], while care was not rated as being important in his study. On the other hand, Måvall and Thorslund [7] report that people with dementia receive more care from relatives than any other group with an illness or disability. However, it is open to question how different relatives see filial obligations and whether the demand for social contact with a person with dementia may be interpreted as a matter of care.

Schulz and Martire [5] refer to resources showing that providing care to a close person with dementia is more stressful than providing care to a person with physical impairment. Different means have been tried to relieve the demands of caring for a demented person, such as psychosocial interventions [2-4, 8-10], that aim at supporting the caregiver and teaching him/her more effective strategies to shoulder the demands. Nichols et al. [4] maintain that nursing home placement may be delayed or avoided by such means of reducing caregiver stress. Other kinds of relief involve certain time-saving procedures or the type of resources that allow the caregiver some time free from caregiving responsibilities, such as home care, home services or day care [11].

Only limited research has been conducted on the effects of day care upon the well-being of individuals with dementia and their caregivers. The study by Zank and Schacke [12] showed significant positive effects of day care on the well-being of the person with dementia and on dementia symptoms. Zarit et al. [13] demonstrated positive effects of day care upon caregivers with regard to the levels of caregiving-related stress and psychological well-being. In light of the results of their study, Gaugler et al. conclude that 'adult day services are potentially effective in restructuring caregiving time and providing respite to family members' [14, p. 55]. However, as these authors point out, the effectiveness of these services may be hard to demonstrate due to the attrition rate of the participants in the study or the short stay of the respective clients in the day-care units. Also, the effectiveness of any intervention is not always clear because the condition of the persons with dementia may have advanced differently at the time of assessing the outcome of the intervention.

Relatives may not seek access to day-care services until late in the disease process [15, 16]. Indeed, Cox emphasizes 'the fact that caregivers tend to delay the use of [respite] programs until the patient is extremely impaired' [16, p. 511]. It is open to question whether the patient's rate of deterioration may not color all methods that are applied to evaluate the benefits of any day-care program. 
Gústafsdóttir: The Family's Experience of Sharing the Care of a Person with Dementia with the Services in Specialized Day-Care Units

\section{Method}

This study is grounded in the interpretive phenomenological approach to research, which has been described in prior reports of this study [17, p. 241]. 'Interpretive or hermeneutical phenomenology is a practice of interpretation and understanding of human concerns and practices. This approach attempts to capture everyday skills, habits, and practices by eliciting narratives about the everyday and by observing action in meaningful contexts' [18, p. 351]. A phenomenological study attempts to get hold of the richness harbored by the real, without seeking to make some specification about the real by synthesizing activity [19]. "The real has to be described, not constructed or formed' [20, p. 82].

The purpose of this interpretive phenomenological study was to explore the collaboration between families and staff in day-care units caring for elderly subjects suffering from dementia. However, it transpired that the term collaboration was interpreted in different ways by the parties in this study. All persons participating in this study seemed to see this phenomenon through the prism of their own realm of contribution to the care of an individual with dementia. The design of the study consisted of three parts: a longitudinal study of the family's experience, group interviews with staff, and participant observation. This paper focuses only on the longitudinal interviews with family members. Previous papers have reported on the participant observation in the day-care units of the study [17] and the staff's interpretation of their care, especially their emphases on health practices of their clients [21].

A longitudinal study has been defined as a study that requires 'obtaining repeated measure over time' [22, p. 560]. Examples of longitudinal studies can be found in quantitative studies such as the Avon Longitudinal Study of Parents and Children (ALSPAC) [23] as well as in other studies of day care $[12,13]$. Risjord points out that 'it is very rare for a qualitative researcher to do a longitudinal study, or even return to the same subjects after the initial project has finished' [24, p. 206]. However, in this case, the researcher did so for the sake of an increased understanding of the phenomenon.

\section{Setting}

The sites of the study were the only three dedicated day-care units for patients with dementia operating in Reykjavík, the capital of Iceland, at the time when the study commenced in 2003.

\section{Participants}

The entire study encompassed a sample of 8 family members and 8 groups of staff (3-4 staff members in each group, a total of 24 staff members). All clients and all staff in these three units were also included in the participant observation. Access to the units was granted by permission of the boards of directors of the respective units.

The 8 family members who participated in this particular longitudinal part of the study were 4 wives, 2 husbands, 1 daughter and 1 daughter-in-law. Being a caregiver to a person admitted to a specialized day-care facility for individuals with dementia was the only prerequisite for participation in the research, as the researcher did not seek permission to check the clients' charts to verify the specific dementia diagnosis.

\section{Interviews}

The author conducted all the interviews herself following an interview guideline accepted by the National Bioethics Committee of Iceland. The number of interviews varied according to the length of stay of the particular individual in the unit. Six interviews were carried out during the longest stay of a particular individual with dementia in one of the day-care units. 
Table 1. Overview of study participants, year of interviewing and times of the sequential interviewing during the different years

$\begin{array}{llllll}2004 & 2005 & 2006 & \text { L } & 2008 & 2009 \\ \text { (T1-T3) } & \text { (T2-T5) } & \text { (T4, T5) } & & \text { (T5) } & \text { (T6) }\end{array}$

\begin{tabular}{|c|c|c|c|c|}
\hline Participant 1 (wife) & $1,2,3$ & $4,5 \rightarrow \mathrm{Nh} \rightarrow+$ & & \\
\hline Participant 2 (wife) & $1,2 \rightarrow \mathrm{Nh} \rightarrow ?$ & & & \\
\hline Participant 3 (husband) & $1,2,3$ & 4 & $5 \rightarrow$ Hospital $\rightarrow \mathrm{Nh} \rightarrow ?$ & \\
\hline Participant 4 (husband) & $1 \rightarrow$ Hospital & $\rightarrow+$ & & \\
\hline Participant 5 (daughter) & $1,2 \rightarrow$ AssL & $\rightarrow \mathrm{Nh} \rightarrow+$ & & \\
\hline Participant 6 (daughter-in-law) & 1,2 & $\rightarrow \mathrm{Nh} \rightarrow+$ & & \\
\hline Participant 7 (wife) & 1 & $2,3 \rightarrow \mathrm{Nh} \rightarrow+$ & & \\
\hline Participant 8 (wife) & 1 & 2,3 & 5 & $6 \rightarrow \mathrm{Nh} \rightarrow+$ \\
\hline
\end{tabular}

$\mathrm{Nh}$ = Nursing home; + = death; AssL = assisted living; ? = unknown if the person is alive or dead. T1: time of the first interview; T2: time of the second interview, etc. Note that there was no research in 2007 (L).

In contrast, only one interview was carried out during the shortest stay of one of the participants with dementia in one of the units.

The initial interview with each family member was scheduled 3 months after the stay of the elderly relative with dementia in the day-care unit, and the next interviews with all participants 3 months later; they then continued about every 6 months until the day care ended (table 1). In all cases but one, the day care ended with a move to a nursing home. The last interview with each family member was carried out shortly after the move. The interview process ended abruptly in one exceptional case, in which the services of the day-care unit ended when the individual was hospitalized. Only one interview with a family member was carried out in that case. All initial interviews were carried out in 2004; however, the duration of the longitudinal process varied. The longest duration of an interview process was 5 years, from end of October 2004 to spring 2009. Each of the interviews with a family member was tape-recorded and lasted about $1 \mathrm{~h}$ (sometimes longer, but never less, including a certain coffee breaks). All tapes were later transcribed to written text.

This extended interview process was an attempt to pinpoint how caregivers of persons with dementia carry on and deal with the progress of the disease. In particular, an attempt was made to reveal how day-care staff would inform the caregivers about ways of dealing with and managing various care demands.

When returning to re-interview a participant, all previous interviews were always read carefully in order to ensure that some aspects that were not fully covered in the former interviews would be inquired in the following one, such as sleeping difficulties or problems with hygiene. Also, any events planned or mentioned in the prior interviews would be addressed in the following one, such as a planned trip to the country or abroad or any special occasion that was foreseen during the interview.

However, during the extended period of interviewing, the interviewees would sometimes say: 'As I have already told you ....'

\section{Ethics}

The research was approved by the National Bioethics Committee of Iceland. Each participant signed a written consent form at the beginning of the interview process. 
Gústafsdóttir: The Family's Experience of Sharing the Care of a Person with Dementia with the Services in Specialized Day-Care Units

\section{Results}

The experience of the particular families of caring for a family member with dementia appeared to be influenced by (a) the multifaceted meaning of ties, (b) the perception of purposeful relief by the day-care services and (c) the progress of the disease.

\section{Data Analysis}

These three themes reflect the main threads that emerged from the author's reading the transcripts of the interviews. The interviews were also listened to, and then the transcript of each interview was read repeatedly in order to discern the main emphases of what each family member said. Next, a comparison was made between the transcripts of the various interviews to pinpoint commonalities as well as dissimilarities in what the different interviewees said. Only the excerpts from the participants' story underpin or verify the author's interpretation. Each of these three themes will be discussed further in order to explain how this interpretation came about.

\section{The Multifaceted Meaning of Ties}

The interpretation of multifaceted meaning of ties bears, on one hand, upon the understanding of close or less-close ties between family members on which caregiving really hinges and, on the other hand, upon the understanding of seeing the caregiver tied, willingly or less so, to the caregiving situation. The caregiving individuals appear to feel that long-standing close ties to the person suffering from dementia endow them with the underlying responsibility and duty of caregiving. The responsibility and duty of caring for a person with dementia often imply continuous closeness while guarding the safety of that person, so the caregiver is very much tied down by the caring situation.

However, it was difficult to define the family ties: somehow, it appeared that the story of the relationship between the person with dementia and the caregiving person could tell more about the quality of the relationship than the strict family connections. The following words of a husband [participant 3, time 2 in the interview process (P3 T2); table 1] provide a vivid insight into how the story of their relationship affected the connection between the couple him and his wife with dementia:

'I try to be as sweet and nice as possible ... it is just as our marriage has been ever since we met, when we were 17 years old ... yes, we got to know each other when we were 17 years old and this person has given me such wonderful times - and I try to stay upbeat.'

Interestingly, the way in which the caregiving person was bound by the caring situation differed in the case of spouses and children. All spouses lived with the person with dementia, while the children lived nearby. This difference in proximity became clear in an interview with a husband (P4 T1) when he said:

'... of course this affects my working hours - I don't go to the office on Saturdays and Sundays and then try to work a bit at home instead, you see. Because if I have to do something then I must of course get somebody to be at home.'

Caregiving children, in contrast, tended to be ready to respond to a telephone call, as a daughter-in- law (P6 T1) said:

'He has all these television stations. There is one thing - he's always phoning because he's mixed up everything and can't find any station. Then his son must run over to his place to put it right.' 
Gústafsdóttir: The Family's Experience of Sharing the Care of a Person with Dementia with the Services in Specialized Day-Care Units

Earlier in this interview the daughter-in-law had said:

'... you know it's becoming difficult to go on holiday, even though we have done so, we've just left our [grown up] children in charge while we are gone. And then he used to come along with us to the summerhouse occasionally, but that isn't possible anymore.'

The interviewer asked if this experience of being tied down by the caring situation was not suffocating - but then the husband referred to earlier (P4 T1) said:

'In a way it is suffocating, yes - or maybe we should rather say restricting.'

But all kinds of ties may ease the caring situation, both for the person with dementia and for the family member in the caregiver's role. Notably, contact with the extended family can bring about a good experience; for example, in one case all children often called at their parents' house after work on Friday afternoons. Both parents enjoyed the visits, according to the mother (P1 T1), and all of them felt that the father suffering from dementia did so too though he did not say much, as his wife said:

'They all come during Friday afternoon - the kids and sometimes their kids as well - and we are just sharing stories of our daily life - talking along - he does not participate, but he seems to enjoy the talking around him - all the same.'

The family members participating in this research were not going to give in easily and seek institutional care as long as the person with dementia could appreciate her/his surroundings at home, as reflected in the following words of a husband (P3 T2):

'... what matters the most for us today, or for me, is to keep my health - because if my health goes - or if I die before her - then there is nothing ahead for her [in the scenario] but an institution .... I haven't applied for any institutions so far - not at all at this stage. I am not doing that, because I shall fight to the last drop of blood ... she loves her home very, very much - we have been here for 38 years.'

Relationships are the bedrock of all ties and are crucial to continuing care at home. But as relationships go awry, they may undermine the caregiver's efforts. A wife (P1 T5) described how her relationship with her husband was changing:

'When we stopped being able to chat, just over dinner together or wherever, because there was only the two of us, it became very wearing - and I couldn't figure out what was wrong. You always think it's something personal.'

This same wife also mentioned, more or less in passing, her husband's increasing difficulty in going to the toilet:

'Now he puts the paper besides the toilet instead of putting it into the toilet.'

But she did not want to dwell on this deterioration of his ability in performing activities of daily living, while she did talk a lot about her declining relationship with her husband. A very dedicated husband (P3 T2) also said:

'I'll keep her with me as long as I am just able to. It is my moral duty to do so. But when the situation comes to that - that I cannot handle things myself - you know - when the situation maybe comes to the point that she doesn't know who I am - then there would be no point in her being at home.'

Ties of this nature form the foundation for caregiving at home, and day-care services can reinforce such ties by mitigating the demands on the caregiver as long as day care serves a purpose for the person with dementia. 
Gústafsdóttir: The Family's Experience of Sharing the Care of a Person with Dementia with the Services in Specialized Day-Care Units

\section{The Perception of Purposeful Relief}

The second theme indicates the perception of purposeful relief and emphasizes that day care was only partly seen as relief for the caregiving family member; this means that day care must also serve a purpose for the person with dementia. So, the theme refers to the family's interpretation of signs that the elderly person is content with the stay in a day-care unit. It was quite clear in all cases that the most important factor in the relief provided by the daycare services was the experience of the person with dementia of attending day care. This stance was very apparent in an interview with a husband (P3 T2) saying:

'I have completely free hands from 9 o'clock in the morning until 4 in the afternoon and I can do whatever I like - not at all being dependent upon her. I can go here, there and everywhere - but then I just think what this has been doing for her - as I was telling you earlier - she looks forward to going [to day care] - obviously she feels good there and she returns [home] pleased, happy and grateful.'

Willingness or unwillingness to attend day care as well as an air of content or discontent upon return from day care are seen as signs that convey how the person with dementia has experienced attending day care [25]. However, problems sometimes occurred in the early stages of attending day care, as a husband (P3 T1) said:

'She was a bit reluctant to begin with, and it still happens on very rare occasions - when I say to her "It's time to be going to day care", and when the alarm clock rings [she will say]: "Oh, do I have to go there now? - I want a lie-in". [But I say] "No, no, you must, my dear. Meet the people there, and so on". And then she gets up and everything's fine.'

At the same time, anything said about the people and the place (the day-care unit) was seen as a sign of either contentment or discontent. These might be incidental comments that reflect the personal meaning of a particular feature of the daily schedule of the person with dementia. The person might, for example, say: 'It was nice singing in the church' (P8 T3).

Interestingly, the air of contentment upon return from day care was very often referred to in terms of 'lightness'. The family member tended to say ... 'I think he is quite a bit lighter' or 'she is a whole lot lighter'. Such perception seemed to mirror the degree to which the burden of disease was seen to be eased by the stay in day care [25]. And thus, the burden of caregiving was also eased. As a husband (P4 T1) said:

'I felt she was doing better after she'd been going to day care for about a month or so - I felt it was doing her good, you see ... she seemed to me to be somehow lighter.'

The husband referred to in an earlier interview (P3 T1) said in the second interview (P3 T2):

'... then there's another thing which is a very significant factor - very significant in the current situation - now she looks forward to each and every day when she is going to day care ... and often she says when she comes home: "It's such fun there".'

It was also very important for the caregiver to know that day care was not simply a 'storage place' but served a purpose for the person with dementia - and the daughter-in-law (P6 T1) was surprised at her father-in-law's response to being in day care:

'We somehow did not think that he would accept it - being "looked after" - but then he turned out to be very happy about it ... he is very pleased, but he does not want to add another 2 days. That option has been available from the very beginning ... but he didn't like the idea - but we've mentioned the possibility, now and again, but it is not in the picture yet.'

\section{The Progress of the Disease}

The deterioration entailed by dementia became clearer step by step as the disease progressed. The two overshadowing symptoms of dementia disease - decreasing memory 
and reduced functional ability $[11-13,26]$ - played their parts in the progress as the condition and well-being of the person with dementia declined. These symptoms were accompanied by behavioral changes; repeated questioning and restlessness proved to be the hardest to cope with. It may be important to note that none of the 8 persons with dementia participating in this study ever displayed any kind of aggressive behavior at home.

The whole scene of caregiving became more difficult to face and handle, especially as the simple tasks of everyday life, such as eating, toileting, personal hygiene, resting and sleeping, became overwhelming. However, the caregivers' threshold of tolerance for the increasing deterioration appeared to be very much influenced by the two previously outlined themes, as the meaning of ties and the day-care experience both had a very powerful influence on the caregiver's staying power. The interplay of these factors became evident in the words of the wife who participated the longest in the interview process (P8 T5), who said:

'I can go on keeping him at home, as long as I have the support of my family, and not least the day-care facility.'

The benefit of day care in this case lied clearly in allowing the man to stay at home longer than his condition and state of illness seemed to permit, as his memory and his functional ability had deteriorated greatly. However, it became evident during the interview process that the ties between the family members and the man with dementia appeared to play an important role in how he was spoken of - the wife always referred to him in terms of a beloved husband and father. In most other cases, the family members' talk was increasingly colored by the symptoms of the disease as the progress of the illness advanced. Sometimes, the family members tended to objectify the person in terms of the disease, but it was hard to tell if the ties in such cases had originally been rather weak or if this way of talking was the consequence of the progress of the illness. Nevertheless, it was not always the change in behavioral patterns that proved to be hardest to bear, but some chronic conditions accompanying the dementia, such as immobility and incontinence, which the person with dementia could not deal with and which could also make the demands of caring very difficult, especially if the spouse was not robust or if the children were not available to help out.

Home care could make a great difference in such cases. However, cooperation with home care did not always work out, and when extensive help was needed it could be experienced as an invasion of the everyday life of the family. For instance, one of the participants, whose husband had, according to his wife, symptoms of Parkinson's disease along with his dementia diagnosis, said that they had really enjoyed all kind of services, such as a 3-week hospital respite every 3 months for her husband for just over 1 year, home nursing, drug delivery, etc. However, she refused more than 3 days per week in the day-care unit for her husband (P2 T1):

'... I only took the third day, even though we could have had 5 days - but I find it a bit much myself, to wake up at 8 o'clock or even earlier every morning, because I always get up with him and give him breakfast and take him down ... and wait for the bus with him - but a woman comes every morning to dress him - except during the weekends - then I do not want it, because then I want to sleep ... it has been like that for more than a year - after he had been in the hospital for respite care.'

\section{Discussion}

The day-care services had great importance for the 8 family members participating in this research. All of them but one had attended support groups: 6 at the Memory Clinic and 1 wife at the day-care unit. They all greatly appreciated psychosocial intervention of this kind and felt it had helped them to shoulder the demands of caregiving [2-4, 8-10]. Interestingly, 
all participants (except the one who was interviewed only once) emphasized the impact of day care on their caregiving at home. The spouse who was interviewed only once pointed out that his wife had had to wait a whole year for a placement in the day-care unit, during which time she deteriorated very much. It has been pointed out that relatives may not seek the assistance of day-care services until late in the disease process $[15,16]$. However, the services may not be available at all or too late in the disease process, as in this case. Nonetheless, the husband, like all the other interviewees, found it especially important that the day care had brought both contentment and structure into the life of the whole family, not least to the person suffering from dementia. The value of the day-care services did not rest entirely on 'restructuring caregiving time' as Gaugler et al. [14] maintained but consisted in restructuring the daily life of the person with dementia [17]. This intervention appeared to strengthen ties within the family and ease the progress of the illness, while day care gave the person with dementia a purpose in waking up in the morning to go to day care. By these means, the caregiver was released for a fixed time from the caregiving situation, so that he/she could in the meantime have freedom of action, knowing that there was no need to worry about how the person with dementia was doing. However, such intervention must be instituted before the illness has advanced too far, otherwise it does not make any sense for the person with dementia and does not serve the caregiving family member.

The caregivers also talked regularly with the head of the day care or the unit's registered nurse and would even mingle with all persons in the day-care facility when they, especially husbands or wives, were invited to participate in events such as trips or dancing sessions. It was noteworthy that the caregivers somehow developed another perspective on the progress of the illness during these occasions and learned from staff to connect with the person with dementia in different ways, so there was less objectifying of the person. Family members would often learn to establish social contact with the person with dementia that may sustain their sense of filial duty as they recognize the possibilities of this important obligation of familial relations, which $\mathrm{Ng}$ [6] has proposed in light of Confucian ethics.

However, as the illness progressed, there was a clearly increasing tendency to speak of the caring situation in terms of the disease. Somehow, the person got more and more lost during the downhill course of the illness, as he/she showed less and less response to any address, and it proved harder and harder to reach out to the person.

\section{Conclusion}

The picture of the disease became clearer all the time, as it became more difficult for the person with dementia to relate to her-/himself, along with the respective person's declining ability to relate to others [22]. The person's ability to relate appeared to be the determining factor in the caregiver's ongoing resilience in keeping the person with dementia at home. A lack of relationships undermined the family ties, and the role of the caregiving family member changed greatly as the person with dementia was not really 'present' any more.

This report addresses the commitment of particular persons caring for those close to them suffering from dementia with regard to their mutual background - the background which makes up the strong ties that form the foundation of the caregiving situation. Such a commitment indicates strong family solidarity which 'is directed towards concrete other and is based on free choice, albeit often accompanied by a strong sense of personal duty' [27, p. 366]. However, this paper also shows how important it is to support the caregivers in coping with the caring situation not least with the help of specialized day-care service. 
Gústafsdóttir: The Family's Experience of Sharing the Care of a Person with Dementia with the Services in Specialized Day-Care Units

\section{Limitations of the Study}

There were only 8 participants in this longitudinal study. However, this report contributes to a larger picture $[17,22]$ and is intended to increase our understanding of the individual experience of being a caregiver of a family member with dementia. It has been pointed out that there are very few empirical studies about the utilization of day care [28]. While it was hard to detect the impact of the day-care staff's input on the matters of caring at home, the staff made the stay in the day care purposeful and helpful; it has also been shown that 'accepting the helpfulness of an offer is a significant predictor for utilization' [28, p. 6].

\section{Acknowledgements}

This study was partly funded by the University of Iceland Research Fund. The help of the registered nurses in contacting the family members is greatly appreciated and so is the willingness of the family members in participating in the repeated interviews. The editor, Anna Yates, has contributed very much to the language of this paper.

\section{Disclosure Statement}

The author has no conflict of interest to disclose.

\section{References}

1 McCracken K, Phillips DR: International demographic transitions; in Andrews GJ, Phillips DR (eds): Ageing and Place: Perspectives, Policy, Practice. London, Routledge, 2005, pp 36-60.

2 Traynor V, Kumiyo I, Crookes P: Literature review: understanding nursing competence in dementia care. J Clin Nurs 2011;20:1948-1960.

-3 Schumacher K, Beck CA, Marren JM: Family caregivers: caring for older adults, working with their families. Am J Nurs 2006;106:40-49.

4 Nichols LO, Martindale-Adams J, Burns R, Graney MJ, Zuber J: Translation of a dementia caregiver support program in a health care system - REACH VA. Arch Intern Med 2011;171:353-359.

5 Schulz R, Martire LM: Family caregiving of persons with dementia: prevalence, health effects, and support strategies. Am J Geriatr Psychiatry 2004;12:240-249.

$6 \mathrm{Ng} \mathrm{SH}$ : Will families support their elders? Answers from across cultures; in Nelson TD (ed): Ageism: Stereotyping and Prejudice against Older People. Cambridge, MIT Press, 2002, pp 295-309.

7 Måvall L, Thorslund M: Does day care also provide care for the caregivers? Arch Gerontol Geriatr 2007;45: 137-150.

-8 Kouri KK, Ducharme FC, Giroux F: A psycho-educational intervention focused on communication for caregivers of a family member in the early stage of Alzheimer's disease: results of an experimental study. Dementia 2011;10:435-453.

-9 Quayhagen MP, Quayhagen M, Corbeil RR, Hendrix RC, Jackson JE, Snyder L, Bower D: Coping with dementia: evaluation of four nonpharmacologic interventions. Int Psychogeriatr 2000;12:249-265.

10 Ulstein ID, Sandvik L, WyllerTB, Engedal K: A one-year randomized controlled psychosocial intervention study among family carers of dementia patients - effects on patients and carers. Dement Geriatr Cogn Disord 2007; 24:469-475.

11 Berry GL, Zarit SH, Rabatin VX: Caregiver activity on respite and nonrespite days: a comparison of two service approaches. Gerontologist 1991;31:830-835.

12 Zank S, Schacke C: Evaluation of geriatric day care units: effects on patients and caregivers. Arch Gerontol Geriatr 2007; 45:137-150.

13 Zarit SH, Parris-Stephens M-A, Townsend A, Green R: Stress reduction for family caregivers: effects on adult day care use. J Gerontol B Psychol Sci Soc Sci 1998;53:S267-S277.

14 Gaugler JE, Jarrott SE, Zairit SH, Paris-Stephens M-A, Townsend A, Greene R: Adult day care service and reduction in caregiving hours: effects on stress and psychological well-being for dementia caregivers. Int J Geriatr Psychiatry 2003;18:55-62. 


\section{DOI: 10.1159/000358823}

(C) 2014 S. Karger AG, Basel www.karger.com/dee

Gústafsdóttir: The Family's Experience of Sharing the Care of a Person with Dementia with the Services in Specialized Day-Care Units

15 Braithwaite V: Reducing ageism; in Nelson TD (ed): Ageism: Stereotyping and Prejudice against Older People. Cambridge, MIT Press, 2002, pp 309-339.

16 Cox C: Findings from a statewide program of respite care: a comparison of service users, stoppers, and nonusers. Gerontologist 1997;37:511-517.

17 Gústafsdóttir M: Beneficial care approaches in specialized daycare units for persons with dementia. Am J Alzheimers Dis Other Demen 2011;26:237-442.

18 Benner P, Tanner CA, Chesla CA: Expertise in Nursing Practice: Caring, Clinical Judgement and Ethics. New York, Springer, 1996.

19 Zahavi D (2008): Phenomenology (B. Porsteinsson, transl.). Reykjavík, The University Press (original work published 2003)

20 Merleau-Ponty M (1962): Phenomenology of Perception (C. Smith, transl.). New York, Routledge (original work published 1945).

-21 Gústafsdóttir M: Keeping-up health promotion practices approaches in specialised daycare units for persons with dementia. Am J Alzheimers Dis Other Demen 2011;26:237-442.

22 Woods NF, Catanzaro M: Nursing Research: Theory and Practice. St. Louis, Mosby, 1988

23 Evans J, Heron JH, Lewis G, Araya R, Wolke D: Negative self-schemas and the onset of depression in women: longitudinal study. Br J Psychiatry 2005;186:302-307.

24 Risjord M: Nursing Knowledge: Science, Practice and Philosophy. Iowa, Wiley-Blackwell, 2010.

25 Gústafsdóttir M: Indicative signs of the elder's contentment with his or her stay in a dementia-based daycare. Int Psychogeriatr 2007;19(suppl 1):84.

26 Rafii M, Taylor C, Coutinho A, Kim K, Galasko D: Comparison of the memory performance index with standard neuropsychological measures of cognition. Am J Alzheimers Dis Other Demen 2011;26:235-239.

-27 Ter Muelen R, Wright K: Family solidarity and informal care: the case of care for people with dementia. Bioethics 2012;26:361-368.

28 Donath C, Winkler A, Graessel E, Luttenberger K: Day care for dementia patients from a family caregiver's point of view: a questionnaire study on expected quality and predictors of utilization - Part II. BMC Health Services Research. http://www.biomedcentral.com/1472-6963/11/76. 